\title{
Atendimento educacional hospitalar em uma perspectiva lúdica: processos educativos emergentes
}

\author{
Hospital educational care from a ludic perspective: emerging educational processes
}

Atendimiento educacional hospitalario desde una perspectiva lúdica: procesos educativos emergentes

\author{
Miriã MARTINS DE BRITO ${ }^{1}$ \\ Universidade Federal de São Carlos, UFSCAR, São Carlos-SP, Brasil
}

\begin{abstract}
RESUMO
Este artigo teve como objetivo central identificar e compreender os processos educativos emergentes da prática social do atendimento educacional hospitalar em uma perspectiva lúdica junto a uma classe de hospital de uma cidade do interior do estado de São Paulo. Consistiu em pesquisa participante com o registro das observações em diários de campo para a coleta de dados. Com base na análise destes construímos a categoria "atenção e cuidado com outrem". Consideramos que a atenção e o cuidado da Educadora da classe hospitalar, a partir da perspectiva lúdica, possibilitaram processos educativos como: amorosidade, diálogo, acolhimento e construção de laços de confiança, contribuindo com a ressignificação do contexto de hospitalização vivenciado pelas crianças.
\end{abstract}

Palavras-chave: Processos Educativos. Atendimento Educacional Hospitalar. Lúdico.

\begin{abstract}
This article aimed to identify and understand the educational processes emerging from the social practice of educational hospital care in a ludic perspective with a hospital class in a city in the interior of the state of São Paulo. The investigation consisted of researching the participant, relying on the systematic record of the analyzes in a field diary as resources for data collection. An analysis of the data enabled the construction of the category "attention and care for others". We believe that the attention and care of the hospital educator, from a ludic perspective, found aspects such as: lovingness, dialogue, welcoming and building bonds of trust, as human principles of the social practice of hospital educational care, contributing to the re-signification the context of hospitalization experienced by children.
\end{abstract}

Keywords: Educational Processes. Hospital Educational Care. Ludic.

\section{RESUMEN}

Este artículo tuvo como objetivo central identificar y comprehender los procesos educativos emergentes de la práctica social de lo atendimiento educacional hospitalario desde una perspectiva lúdica junto a una clase de hospital en una ciudad en el interior del estado de São Paulo. Consistió en investigación participante con lo registro de las observaciones en diarios del campo para la coleta de datos. Con base en el análisis de eses construimos la categoría "atención y cuidado con otren". Consideramos que la atención y lo cuidado de la Educadora de la clase en hospital, desde la perspectiva lúdica, posibilitaran procesos educativos como: amorosidad, diálogo, acojínenlo y construcción de lazos de confianza, contribuyendo al re-significación del contexto de hospitalización vivenciado por los niños.

Palabras clave: Procesos Educativos. Atendimiento Educacional Hospitalario. Lúdico.

\footnotetext{
${ }^{1}$ Doutoranda no Programa de Pós-Graduação em Educação da UFSCar. E-mail: mihmartins23@hotmail.com. ORCID: http://orcid.org/0000-0001-8031-9705.
} 


\section{INTRODUÇÃO}

A hospitalização é um processo delicado na vida de qualquer pessoa, sobretudo para crianças, ainda em formação e que requerem mais a proximidade dos pais e familiares. Ansiedade, preocupação, sensação de abandono, tristeza, medo e insegurança, são alguns dos sentimentos que podem potencializar experiências negativas e traumáticas para as crianças hospitalizadas, deixando marcas profundas em suas vidas (RIBEIRO; ÂNGELO, 2005).

No que concerne aos desafios que envolvem a infância e a busca pelos direitos do cuidado integral das crianças hospitalizadas, a continuidade do seu desenvolvimento em ambiente hospitalar é compreendida como potencial para trocas e aprendizagens significativas quando ocorre através de um olhar sensível e um trabalho humanizado. As crianças em tratamento de saúde podem aprender a vivenciar novas descobertas, ressignificando suas vidas, levando em conta as experiências advindas das situações que as cercam no contexto hospitalar (GONÇALVES; MANZINI, 2011). Nesse sentido, o cuidado e a educação são intrínsecos no processo de desenvolvimento da criança, amparados em documentos nacionais, tanto na Educação Infantil (BRASIL, 2009), quanto para as crianças dos anos iniciais do Ensino Fundamental (BRASIL, 2007), a compreensão do cuidar e educar são elementos fundamentais para as etapas educacionais que compõem a infância.

A interação entre os campos da Educação e Saúde busca o cuidado integral à criança hospitalizada contribuindo com a continuidade do seu desenvolvimento, através do Atendimento Educacional Hospitalar. Tal atendimento é apresentado na legislação brasileira como garantia do direito à educação de crianças e jovens que estejam em tratamento de saúde. Essa assistência pode ser realizada junto aos leitos, brinquedotecas ou em Classes Hospitalares, esse último sendo um espaço específico para esse atendimento (BRASIL, 2002).

O Atendimento Educacional Hospitalar, mesmo que por breves momentos no dia, pode retirar e desvincular as crianças do contexto da doença, envolvendo-as em atividades educacionais, brincadeiras e jogos, possibilitando a aproximação com uma rotina anterior à entrada no hospital (MEDEIROS; GABARDO, 2004). Compreendendo a importância do atendimento educacional hospitalar e os desafios que envolvem esse direito, a Classe Hospitalar mostra-se como espaço de trocas significativas entre as crianças e os/as educadores/as nesse ambiente.

Conforme apresentam Oliveira et al. (2014) as interações que surgem entre diferentes pessoas podem ser entendidas como práticas sociais que se desenvolvem no interior de comunidades, coletivos, associações, instituições, de maneira que transmitem significados, valores e repassam conhecimentos e perspectivas diante da vida, buscando conquista ou garantia de direitos e o respeito e valorização de pessoas e grupos socialmente marginalizados. Do interior das mais diversas práticas sociais, escolares e não escolares, se dão processos educativos, pois todos os/as partícipes envolvidos/as são capazes de fazer a sua leitura de mundo, reconhecer outrem e se reconhecer, significar e ressignificar sua vida e dirigir-se ao ser mais ${ }^{2}$. Compreendemos que processos educativos se dão:

[...] em uma relação mútua de aprendizagem e não só em uma situação em que um ensina ao outro, tendo como pressuposto fundamental para seu desenvolvimento o diálogo equitativo e a intencionalidade dirigida para a

\footnotetext{
${ }^{2}$ Conforme Freire (2017), somos seres condicionados, mas não determinados, logo inconclusos e dotados da possibilidade existencial de transcendência, de "ser mais".
} 
cooperação, superação, o ser mais, demandando autonomia, possibilidade de decisão e de transformação. Tais condições permitem aos envolvidos compreender em contexto, valores e códigos do grupo, da comunidade e da sociedade em que vivem, tendo a possibilidade de refletir criticamente sobre sua própria condição de pertencimento ao mundo com os outros, educando e educando-se, tornando-se pessoa (GONÇALVES JUNIOR; CARMO; CORRÊA, 2015, p. 176-177).

Ao pesquisar processos educativos em ambientes escolares não convencionais, especificamente na Classe Hospitalar, o/a pesquisador/a deve se posicionar a partir de um olhar sensível e humanizado para as relações que são estabelecidas nesse contexto, buscando desenvolver sua investigação com todos/as envolvidos/as nesse processo, de maneira que a construção do conhecimento seja coletiva e dotada de potencialidade para a transformação e/ou ressignificação da realidade na qual se insere a criança hospitalizada.

Registrando entendimento da Classe Hospitalar como um tempo-espaço não apenas de sala de aula no hospital, mas como o momento de atendimento educacional especializado com o objetivo de possibilitar a restauração da socialização da criança e do/a jovem por meio da inclusão e, consequentemente, contribuição na continuidade de seu desenvolvimento integral (OLIVEIRA; SOUZA FILHO; GONÇALVES, 2008; FONTES, 2005).

Destarte este artigo teve como objetivo central identificar e compreender os processos educativos emergentes da prática social do atendimento educacional hospitalar em uma perspectiva lúdica junto uma classe de hospital de cidade do interior do estado de São Paulo.

\section{ASPECTOS DO ATENDIMENTO EDUCACIONAL HOSPITALAR NO BRASIL}

O Atendimento Educacional Hospitalar surgiu em meados do século XX, na França, após a Segunda Guerra Mundial (1939-1945), quando um considerável número de crianças e adolescentes foram feridos e mutilados em consequência da Guerra. No Brasil esse atendimento é datado por volta de 1950, no Hospital Menino Jesus, no Rio de Janeiro, embora alguns estudos indiquem como marco da educação no hospital, o período do Brasil Colônia em que o atendimento educacional hospitalar era oferecido na Santa Casa de Misericórdia de São Paulo (OLIVEIRA, 2013).

A partir do incentivo de médicos, voluntários e religiosos, o atendimento educacional hospitalar foi ganhando espaço na sociedade, sendo divulgado e organizado em diferentes países como Alemanha e Estados Unidos, posteriormente ganhando presença no Brasil com o termo "Classe Hospitalar" na Política Nacional de Educação Especial em $1994^{3}$, assegurando o atendimento educacional de crianças e jovens que estejam em tratamento no ambiente hospitalar (BRASIL, 1994). Em 1995, a Resolução $\mathrm{n}^{\mathrm{o}}$ 4, reafirmou, através do Estatuto da Criança e do Adolescente Hospitalizado, o direito de acompanhamento curricular escolar, bem como programas de escolarização e recreação no decorrer do período de hospitalização de crianças e adolescentes (BRASIL, 1996).

\footnotetext{
${ }^{3}$ Em 1994 foi lançada a Política Nacional de Educação Especial (BRASIL, 1994), sendo substituída em 2008 pela Política Nacional de Educação Especial na Perspectiva da Educação Inclusiva, apontando a atuação no Atendimento Educacional Especializado (AEE) também nas classes hospitalares e nos ambientes domiciliares (BRASIL, 2008).
} 
Em 2001, diante da necessidade de amparar o atendimento educacional de forma mais especifica, foram propostas as Diretrizes Nacionais para a Educação Especial na Educação Básica (BRASIL, 2001), buscando a sistematização do atendimento através das classes hospitalares e o atendimento domiciliar. Um ano depois, o Ministério da Educação (MEC) lançou o documento "Classe Hospitalar e Atendimento Pedagógico Domiciliar: estratégias e orientações" (BRASIL, 2002), visando assegurar a garantia desse serviço, apresentando direções e ações para a prática do atendimento educacional hospitalar.

Recentemente, a Lei 13.716/2018 (BRASIL, 2018) alterou a Lei de Diretrizes e Bases da Educação Nacional-LDB (BRASIL, 1996), apresentando o direito específico do atendimento educacional hospitalar no Art. $4^{\circ}-\mathrm{A}$. "É assegurado atendimento educacional, durante o período de internação, ao aluno da educação básica internado para tratamento de saúde em regime hospitalar ou domiciliar por tempo prolongado" (BRASIL, 2018).

Contudo, mesmo com respaldo legal, a garantia do direito educacional no âmbito hospitalar, na prática, ainda é uma realidade distante. Muitas vezes, a tramitação burocrática entre a Secretaria da Educação e a Secretaria da Saúde, ou ainda a ausência de aproximação entre ambas, podem levar ao distanciamento de ações efetivas, dificultando a instalação de mais classes hospitalares. Dessa maneira, "[...] os desafios que se colocam na garantia do direito estão voltados para a vontade política e os olhares mais humanos e menos assistencialistas nesse setor" (ZAIAS; PAULA, 2010, p. 224).

Além das dificuldades anteriormente citadas, os estereótipos existentes sobre a incapacidade da criança de continuidade no seu desenvolvimento educacional no hospital devido as fragilidades que a doença pode trazer, somada a uma percepção tecnicista da parte de alguns profissionais da saúde acerca do cuidado, acabam por invisibilizar a criança hospitalizada como sujeito aprendente, dotado de direitos e autonomia. Entendemos, em acordo com Paula e Soares (2018), que o afastamento da escola regular não pode levar à exclusão desses/as estudantes, a hospitalização não deve ser empecilho para o desenvolvimento integral da criança.

Ademais ao se ignorar os aspectos atrelados ao desenvolvimento da criança em sua formação humana, a hospitalização, se não assistida com Classes Hospitalares, pode prejudicar a progressão regular do ensino, levar à evasão escolar e ainda acabar por cercear as oportunidades desta como cidadã de direito a uma vida de qualidade (FONTES, 2005).

Dessa forma, a dimensão de escola no hospital observa necessidades especificas para o processo de recuperação da criança hospitalizada, pois através da continuidade dos estudos em um ambiente tão peculiar e em um momento tão delicado, a criança pode ser tranquilizada ao sentir-se capaz, valorizada e incluída, desconstruindo o eventual sentimento de incapacidade advindo do adoecimento e da hospitalização e contribuindo para o seu fortalecimento diante de situações adversas (OLIVEIRA, 2013).

\section{O LÚDICO COMO PERSPECTIVA NO ATENDIMENTO EDUCACIONAL HOSPITALAR}

Em muito o lúdico está associado ao universo da criança e aos efeitos do brincar no desenvolvimento infantil, e nesse sentido, ganha força no campo da Educação. A origem semântica de lúdico é proveniente do latim ludus, significando exercício, imitação e jogo (MASSA, 2017). Conforme Cardoso (2011, p. 47): "Historicamente, o conceito de lúdico está relacionado às ideias de jogo, brincadeira, recreação e lazer; mas 
é importante ater-se para o fato de que a ludicidade ultrapassa tais aspectos", conforme Massa (2017) refere-se ao estado de ânimo do ser.

Cardoso (2011) afirma que o lúdico vinculado à educação escolar é fundamental pelo apoio oferecido ao desenvolvimento integral da criança. Ao brincar os laços se estreitam de modo que a criança pode se autoconhecer e a se relacionar com outras pessoas, favorecendo ao mesmo tempo o encanto de aprender e construir $\mathrm{o}$ conhecimento de maneira prazerosa.

Marinho e Pimentel (2010) observam que embora o lúdico ocupe lugar de destaque na Educação, ainda é um objeto intrigante para ser delineado, sendo que, em alguns casos, o lúdico será compreendido como semelhante às manifestações denominadas como jogo, brincadeira, festa, e alertam para a maneira descontextualizada em que o lúdico muitas vezes é apresentado. Neste sentido Massa (2017) acrescenta que o lúdico não se define em uma atividade, antes é o estado de ânimo do indivíduo a partir das práticas lúdicas que o mesmo pode fruir.

Quando o lúdico é compreendido e valorizado a criança e seu desenvolvimento escolar também são, pois o brincar abre possibilidades de descoberta, criatividade e transformação, auxiliando na imaginação da criança e, desse modo, incentivando-a em relação à continuidade de seus estudos (CARDOSO, 2011). As ações em uma perspectiva lúdica podem contribuir com o desenvolvimento integral ao ativar os sentimentos de bem-estar na criança, não somente durante, mas após a realização dessas atividades (DUARTE, 2017).

Pinto (2007) ressalta que as atividades lúdicas possibilitam que as pessoas brincantes tornem-se parceiras, corresponsáveis e cúmplices nos jogos e brincadeiras. Ao ocupar o eixo central na experiência lúdica que surge desde a curiosidade, energia criativa, crítica e transformadora de cada ser, evocam também desejos, imaginação e poder de escolha para buscar a superação dos desafios impostos. Massa (2017) complementa que as práticas lúdicas favorecem o autodesenvolvimento também do/a mediador/a responsável por esse momento, exigindo um "estar presente" inteiramente nesse processo como docente, viabilizando essa mesma chance para os/as estudantes.

Quando voltamos a atenção às contribuições da ação lúdica para o desenvolvimento infantil, um fator preocupante emerge em relação às crianças que estão hospitalizadas em decorrência de um tratamento de saúde. Antes de adentrarem o universo hospitalar essas crianças podiam brincar com seus/suas amigos/as na rua, na escola, em suas casas, podiam também estudar, passear e explorar o mundo com maior liberdade (CARDOSO, 2011). Assim, conforme Vendramin, Fernades e Mattão (2016), ao propor a perspectiva lúdica no Atendimento Educacional Hospitalar, o/a educador/a torna as atividades mais instigantes e dinâmicas para mediação no processo de ensino e de aprendizagem, possibilitando a exploração de novas situações e contextos e a expressão dos sentimentos pelas crianças com maior facilidade ao interagir e brincar. Ao despertar a interação da criança através da brincadeira, o/a profissional contribui com parte da retomada do cotidiano anterior à hospitalização, impulsionando o processo de cura e recuperação das crianças hospitalizadas.

Deste modo, é relevante considerar a perspectiva lúdica no contexto hospitalar, pois esta colabora para a integração entre as crianças hospitalizadas, a equipe de saúde e o/a educador/a da Classe Hospitalar. Nesse ponto, adentramos as ações que esse/a profissional pode desenvolver com as crianças da Classe Hospitalar, como teatro de fantoches, livros sensoriais, leitura e músicas infantis, jogos e brincadeiras, atividades que podem influenciar diretamente o emocional da criança hospitalizada, favorecendo a mudança de humor e a melhor adaptação ao ambiente (DUARTE, 2017). 
Portanto, fundamental, hospitais oferecerem a continuidade dos vínculos escolares, sobretudo pelo viés lúdico, por meio das classes e das brinquedotecas hospitalares, por exemplo. Em ambos os espaços o/a educador/a pode desenvolver práticas que permitam com que as crianças extrapolem eventuais sentimentos negativos advindos da hospitalização, pois ao entrar ao mundo lúdico, a criança pode nutrir sua vida interior, vivenciando momentos reconfortantes e prazerosos (CARDOSO, 2011). Concordantes com estas ideias, Vendramin, Fernades e Mattão (2016), expressam que o/a educador/a deve perseverar em seu trabalho, construindo projetos específicos e adaptados para crianças no contexto hospitalar, de modo que a valorização da autoestima das mesmas as fortaleça na superação dos desafios e dos estereótipos ao entorno da capacidade de aprender nesse ambiente.

Completamos nosso entendimento acerca da perspectiva lúdica no Atendimento Educacional Hospitalar, em conformidade com as autoras Mineiro e D’Ávila (2019):

A ludicidade é elemento estruturante, um meio, uma linguagem que pode permear todo o fazer docente, o instrumento que pode, em consonância com os outros instrumentos da orquestra educativa, tocar uma enternecedora canção de ressignificação (p. 13).

\section{Metodologia}

Na pesquisa participante é relevante melhor conhecer dado fenômeno para abrir caminhos em que as pessoas sintam-se motivadas a buscarem transformação de seus contextos sociais, de suas vidas e de seus destinos. Assim, deve estar situada e levar em conta a totalidade, estrutura e dinâmica de determinado tempo-espaço. A ação da pesquisa, ainda que em locais específicos e parciais, refletindo somente uma parte de toda uma vida social, deve considerar as interações que corroboram com os alicerces e as dinâmicas desta mesma sociedade (BRANDẪO; BORGES, 2008).

Assim, tanto a necessidade quanto os procedimentos de pesquisa a selecionar se definem a partir das inquietações e dos desafios que vão surgindo no decurso das interações com as pessoas participantes em seu lócus, de modo que "[...] o processo e os resultados de uma pesquisa interferem nas práticas sociais, e, de novo, o seu curso levanta a necessidade e o momento da realização de novas investigações participativas" (BRANDÃO; BORGES, 2008, p. 54).

Para Brandão (2006), a pesquisa participante também parte do princípio de que não existe neutralidade e nem objetividade na ciência, de maneira que a confiabilidade da pesquisa está na colaboração "[...] de sua prática na procura coletiva de conhecimentos que tornem o ser humano não apenas mais instruído e mais sábio, mas igualmente mais justo, livre, crítico, criativo, participativo, corresponsável e solidário" (p. 24). Envolve uma relação de igualdade entre o/a pesquisador/a e os/as colaboradores/as, de maneira que todas as pessoas e as diferentes culturas são compreendidas como fontes primárias de saber.

Conforme Brandão e Borges (2008) um verdadeiro compromisso de presença e participação deve ser assumido na pesquisa participante, criando vínculos solidários e nunca de imposição de valores e conhecimentos. Entendem como fundamental na pesquisa participante: conhecer, desvelar, compreender para formar sujeitos motivados a transformação das conjunturas sociais de seus mundos-vida, destinos e trajetórias.

Com tais premissas, esta investigação buscou identificar e compreender os processos educativos emergentes da prática social do Atendimento Educacional Hospitalar em uma perspectiva lúdica junto a uma classe de hospital de cidade do 
interior do estado de São Paulo, contando com os seguintes procedimentos: Aproximação e Inserção em Campo, Coleta de Dados e Análise de Dados, conforme descrições a seguir.

\section{PROCEDIMENTOS DE APROXIMAÇÃO E INSERÇÃO EM CAMPO}

Oliveira et al. (2014) ressaltam a necessidade do/a pesquisador/a inserir-se nos tempos-espaços de investigação com cautela, de modo que a convivência seja baseada no estabelecimento de vínculos de respeito e de confiança mútuos, iniciados no momento que o/a pesquisador/a se apresenta, deixando explicito que é alguém que quer participar desde dentro e com as pessoas envolvidas nessa prática social, de modo que possa identificar e compreender processos educativos que dali emergem.

A inserção em campo deve considerar a construção de relações nesse tempoespaço por meio do convívio, procurando humanizar e humanizar-se nessas relações, por meio da amorosidade, colaboração, empatia e respeito. É por meio da convivência que se dá o cuidado de não ver as pessoas como objetos e assumimos o compromisso ético de fazer pesquisa com e não sobre pessoas, grupos e comunidades (OLIVEIRA et al., 2014).

Dessa forma, a investigação foi desenvolvida em uma instituição de saúde situada em uma cidade localizada no interior do estado de São Paulo. O primeiro contato foi feito através de uma carta eletrônica de apresentação explicitando a proposta da pesquisa ao Departamento de Pesquisa e Ensino do Hospital $^{4}$, de maneira que a Coordenadora respondeu ao pedido solicitando espera para possível análise e aprovação de outras instâncias da instituição.

Após aprovação da pesquisa pela equipe do local pretendido, bem como da autorização das crianças e de seus pais, mães e/ou responsáveis, nos aproximamos da Educadora responsável pela classe hospitalar desta instituição, sendo possível o acompanhamento da rotina educacional hospitalar estabelecida por esta profissional. Logo pela manhã a Educadora tinha acesso ao prontuário médico da ala pediátrica, que sinalizava entradas no hospital e informações, como o motivo e o período estipulado para o tratamento, o/a médico/a responsável pelo caso e a idade de cada criança. $\mathrm{Na}$ Classe Hospitalar dessa instituição o perfil de atendimento dos/as usuários/as da saúde é de crianças a partir dos três anos em diante, também de crianças em idade escolar do $1^{\circ}$ ao $5^{\circ}$ ano do ensino fundamental. São, na maioria dos casos, crianças acometidas por doenças crônicas respiratórias que passam um período de internação em torno de uma semana.

Depois de checar o quadro de crianças hospitalizadas no dia, a Educadora visitava aquelas que já estavam encaminhadas para a internação, estabelecendo um primeiro contato buscava desenvolver uma conversa apresentando seu trabalho à criança e aos familiares, e, além disso, aproveitava para identificar aspectos como: o que as crianças já conheciam daquele ambiente e em que fase da aprendizagem se encontravam, observando algumas características relacionadas ao comportamento, à linguagem, à reação e à compreensão delas quanto a hospitalização. Dessa forma, acontecia uma sondagem para depois ser realizado contato com a escola de origem e a proposição de atividades.

A inserção em campo neste estudo envolveu seis encontros, desde a aproximação dos/as profissionais, passando pelo conhecimento da dinâmica do hospital até o

\footnotetext{
${ }^{4}$ Agradeço a atenção dada pela equipe do hospital. Por motivos éticos de confidencialidade em pesquisa, o nome da instituição e de todos/as os/as envolvidos/as são mantidos em sigilo.
} 
acompanhamento das atividades em Classe Hospitalar. Durante o período de inserção foi contabilizado entre duas a quatro horas diárias no ambiente hospitalar no acompanhamento junto à professora em seu atendimento educacional.

\section{Procedimentos de COleta de dados}

$\mathrm{Na}$ coleta de dados desse estudo utilizamos registro sistemático das seis observações de cada um dos seis encontros em diários de campo para posterior análise. Tais diários tiveram foco específico na prática social do Atendimento Educacional Hospitalar, e explicitam a memória desta pesquisadora, em intersubjetividade com os/as colaboradores/as do estudo na forma de uma descrição densa, conforme proposto por Costa (2002).

Os diários possuem um momento descritivo, isto é, com detalhados relatos relacionados à captura dos espaços, gestos, pessoas, situações observadas; e outro reflexivo, envolvendo reflexões pessoais da pesquisadora diante dos acontecimentos vivenciados com os/as colaboradores/as no tempo-espaço da pesquisa de campo. Ao equilibrar as partes descritivas e reflexivas, os diários de campo tornam-se indispensáveis para a validação de uma investigação qualitativa, auxiliando de modo significativo na melhoria do processo de apresentação dos dados coletados para sua posterior análise (BOGDAN; BIKLEN, 1994).

\section{Procedimento de ANÁlise dos dAdOS}

A partir da inserção no hospital e da participação com os/as colaboradores/as naquele contexto, foi possível o levantamento de dados acerca do Atendimento Educacional Hospitalar. De posse destes seguimos para análise dos dados pautando-nos na proposição de Gomes (2002), a qual prevê: Ordenação, Classificação e Análise Final. Assim, em um primeiro momento foi realizada a leitura e releitura dos seis diários de campo, organizando o material entre as descrições e reflexões; em seguida, a partir das leituras exaustivas do material coletado e dos textos bases, estabelecemos questionamentos para identificação do que entendemos relevante com base no objetivo do estudo e construímos as categorias de análise, portanto, a posteriori. No terceiro momento, realizamos a análise e interpretação dos dados registrados nos diários de campo (apresentados pelas iniciais DC e, após hífen, o número da ocorrência em algarismos romanos, exemplo: DC-I, DC-II e assim por diante) com os referenciais teóricos possibilitando as considerações da pesquisa.

Destarte, construímos a categoria temática “Atenção e Cuidado com Outrem”, conforme segue.

\section{Atenção e Cuidado COM OUTREM}

O acompanhamento da rotina da Educadora possibilitou a compreensão do lúdico como delineador das atividades por ela elaboradas para o Atendimento Educacional Hospitalar. As brincadeiras e jogos desenvolvidos na brinquedoteca e junto ao leito das crianças hospitalizadas firmavam interações significativas entre elas e a Educadora. Quando a criança era encaminhada para a internação, automaticamente ocorria uma conversa entre o/a educando/a e a Educadora para identificação de aspectos relevantes, 
como a linguagem e capacidade de expressão e comunicação dessa criança, em que fase da aprendizagem ela se encontrava e sua percepção e reação sobre o processo de hospitalização. Dessa forma, aconteceu uma espécie de sondagem para posteriormente ser realizado o contato com a escola e a elaboração de atividades (DC-II). Nesse momento, toda atenção e cuidado já estão presentes na prática da Educadora que realizou o atendimento, tornando crucial o zelo pelo trabalho desenvolvido desde esse instante.

Ainda no segundo encontro a Educadora comenta acerca do seu interesse pela atuação na Classe Hospitalar:

[...] como compromisso responsável de fazer o seu melhor com as crianças, que procura estar atenta, não somente a seu fazer pedagógico, mas a outros aspectos que envolvem a hospitalização e o universo da criança e da família. Disse também que não sabe fazer tudo, mas procura aprender com outros colegas de trabalho da Educação Especial, através de conversas e congressos. Disse ainda que no exercício da profissão foi aprendendo a olhar e a perceber as coisas (DC-II).

Em outro encontro a Educadora organizou uma atividade escolar para Sofia ${ }^{5}$, de cinco anos, dando ênfase para essa faixa etária, considerando também no planejamento o incentivo, a escrita e a leitura lúdica em uma atividade que envolvia a contação de história:

[...] fomos até a brinquedoteca e escolhemos o livro "As Cerejas Teimosas". Utilizamos como recurso o computador da sala de multiprofissionais e fizemos um jogo da memória para colorir, com figuras dos alimentos que o livro continha: frutas e legumes. A intenção era conversar sobre isso e propor para Sofia diferenciar frutas de legumes. Voltamos ao leito para buscar a garota, fizemos a contação de história e depois desenvolvemos a atividade (DC-II).

No momento de aproximação entre Educadora, Pesquisadora e crianças hospitalizadas, as interações proporcionadas pelo lúdico foram fundamentais, auxiliando a construção de um laço mais estreito entre as pessoas, isto é, de confiança entre Educadora, Pesquisadora, crianças, seus familiares, outros/as profissionais da equipe do hospital.

Nessa investigação, especificamente para Sofia, a experiência lúdica abriu portas para que pudesse expressar o que tinha vontade naquele momento, sobre o que gostava de comer, acerca da sua família, comentando inclusive seu nome completo e de seus irmãos (DC-II). A fruição lúdica favoreceu estabelecimento do processo educativo de confiança e início da construção de um vínculo, à medida que Sofia se sentia segura com a Educadora e com a Pesquisadora, melhor se sociabilizava e interagia a partir da visão de mundo dela, ressignificando e compartilhando sua compreensão daquele contexto como algo passageiro em sua vida, referindo-se à sua família e contando sobre seu dia-a-dia fora do ambiente hospitalar, informando a Pesquisadora: "[...] seu nome é igual o da minha tia, assim que eu sair daqui vou contar pra ela" (DC-II).

A atenção e o cuidado com outrem são essenciais enquanto processos educativos que favorecem a expressão dialógica da criança, com a Educadora, a Pesquisadora, os familiares e as demais crianças, desde sua forma de ser e sentir-se no e com o mundo, pronunciando sua compreensão dele. Freire (1992) aponta que o ato de dizer a palavra

\footnotetext{
5 O nome desta e das demais duas crianças deste estudo são fictícios, conforme preceitos éticos, preservando a identidade das mesmas.
} 
não é algo simples, como apenas redizer o que já foi dito, mas é também "reviver o vivido".

Boff (2006) ressalta a convivência horizontal em que os/as envolvidos/as se veem e se mostram em um mesmo nível de importância, caminho que concede a ambas as partes o estar junto, o coexistir, o trocar, essenciais para a constituição de qualquer relação.

Em uma das interações identificamos que:

[...] Laura, de três anos, aparentava timidez, esfregava os olhos quando direcionávamos a palavra a ela como que se quisesse esconder o rosto. [...] por mais que perguntássemos algo, ela respondia apenas acenando a cabeça em sinal afirmativo ou negativo. A Educadora passou algum tempo tentando interagir, mas ela continuou brincando com um livro que estava nas mãos dela [...]. A Mãe da Laura disse-nos que perto dos pais ela se comportava assim mesmo e era bem tímida. Uma enfermeira que precisava fazer procedimento de lavagem no nariz da criança adentrou o quarto e neste interim ficamos conversando um pouco com a Mãe da garota. Depois do procedimento, voltamos a falar com ela e propomos que voltaríamos depois, quando ela estivesse sozinha, sem a Mamãe, ela aceitou (DC-III).

Laura não se sentia à vontade, de modo que a Educadora reconsiderou o desenvolvimento de qualquer atividade naquele momento, pois a intervenção hospitalar ocasionou desconforto à criança.

Passado algum tempo fomos para a brinquedoteca e encontramos Laura e, conforme combinado, a Mãe nos deixou a sós com ela. [...] Enquanto a Educadora montava uma mesinha com alguns brinquedos, tentei uma aproximação, brincamos de montar pecinhas e fui iniciando um diálogo. A garota se sentiu mais à vontade. Em seguida a Educadora propôs jogo de esconder um brinquedo, Laura concordou e brincamos ao menos três vezes seguidas (DC-III).

Muitas vezes as relações dentro da lógica capitalista, de caráter imediatista, limitam-se a serem construídas de modo rápido, sem a perseverança e tranquilidade para sustentação de vínculos (BAUMAN, 2014), como neste estudo, de atenção e cuidado com outrem, impossibilitando a experiência de compreender a complexidade e ao mesmo tempo a magnitude da convivência. Mesmo em um contexto hospitalar, marcado pela rotatividade de pessoas, tanto daqueles/as em tratamento de saúde, como da própria equipe de funcionários/as em seus diferentes turnos, a convivência e o diálogo são fundamentais para a construção das relações nesse ambiente.

Depois também propusemos que Laura contasse-nos histórias, justamente porque havíamos percebido que apesar de falar e articular as palavras e formar as frases perfeitamente, ela ainda pouco se expressava a nós. Para nossa surpresa ela aceitou contar três histórias: "Os Três Porquinhos"; "Cinderela" e "Branca de Neve". Em seguida, perguntamos se ela gostaria de colorir desenhos referentes às histórias. Ela prontamente aceitou a proposta (DC-III).

Foi no decorrer dessa prática que a Educadora, a Pesquisadora e a Laura construíram uma relação de convivência facilitada pela mediação lúdica, permeada dos processos educativos de atenção e cuidado com outrem. A partir de então, junto à Educadora e à Pesquisadora, Laura pôde expressar suas necessidades, curiosidades e interesses de modo verbal. "Foi incrível ver como Laura sentia-se mais à vontade. Além 
de contar as histórias, conversou bastante" (DC-III). Com sensibilidade, amorosidade, atenção e cuidado com outrem a Educadora percebeu a necessidade do tempo, da calma e do diálogo para a construção de uma relação de confiança com a criança hospitalizada, daí ter aguardado passar o desconforto da intervenção realizada em Laura para retomar as atividades conforme registrado no DC-III.

De acordo com Freire (2017, p. 113), “[...] o diálogo se faz uma relação horizontal, em que a confiança de um pólo no outro é consequência óbvia". E prossegue, “[...] não há diálogo, porém, se não há um profundo amor ao mundo e aos homens [e mulheres]. Não é possível a pronúncia do mundo, que é um ato de criação e recriação, se não há amor que a infunda" (p. 110).

A mediação lúdica, através da proposição de jogos e brincadeiras, favorece com que a criança se expresse, converse e construa significações no seu cotidiano. Brincar e amar, como descreve Maturana e Verden-Zoller (2004), são modos de vida e relação que orientam essencialmente todas as proporções da coexistência humana.

Sem ampliar a visão a que o amor conduz - e sem liberdade para a mudança de vida trazida pelo brincar -, a reflexão sobre o nosso próprio viver torna-se impossível [...]. Só o enlace do amor com a brincadeira permite a reflexão, pois eles se apoiam no auto e hétero-respeito (MATURANA; VERDENZOLLER, 2004, p. 255).

A vivência lúdica é única para cada ser humano, permitindo com que experimente com plenitude os estímulos, as aprendizagens e a harmonia entre as pessoas nesse envolvimento (MASSA, 2017) e, para a criança hospitalizada, embora tal circunstância possa trazer como marca o "não brincar", formas de fruição do lúdico nesse contexto podem se desenvolver e proporcionar contributos ao tratamento (SANTOS et al., 2016). O brincar ganha força ao despertar os sentimentos de alegria, superação, prazer e satisfação, compreendendo o lúdico de forma integral (CARDOSO, 2011). Desse modo, "[...] segue-se que o brincar, como relação interpessoal, só pode acontecer no amor; que uma relação interpessoal que ocorre no amor é necessariamente vivida como brincadeira" (MATURANA; VERDEN-ZOLLER, 2004, p. 224).

Brandão (2006) complementa que o amor como um afeto que se ensina e se aprende a partir da convivência com outrem, se trata de "[...] uma prática múltipla e fecunda que se comparte [...], o amor é uma experiência a ser partilhada em qualquer situação em que pessoas se reúnam para construir os saberes e sentidos de suas vidas" (p. 47).

Atenção e cuidado com outrem estava frequentemente presente nas relações construídas pela Educadora com cada uma das crianças hospitalizadas. Em um dos encontros da pesquisa de campo a Educadora esteve com Carlos, de dez anos de idade, pessoa com deficiência física e cognitiva, o qual era recorrentemente internado, conforme informou a Educadora, a qual, mais uma vez interagiu com atenção e cuidado, conforme segue:

A Educadora se mostrou preocupada com a posição rígida em que Carlos ficou da última vez em que a viu, perguntou as médicas presentes se o garoto se encontrava bem. As profissionais relataram que há certa complexidade no quadro dele, mas disseram que a posição rígida pode ter sido ocasionada por tensão. Era um dia em que ele estava tenso. Além disso, ressaltaram dificuldades em deixá-lo em outras posições, já que o avô não concorda com a possibilidade de mudar o garoto de lado e sempre o deixava do mesmo jeito, o que estaria sendo prejudicial inclusive para a postura dele (DC-II). 
Em acordo com Maturana e Verden-Zoller (2004, p. 256) “[...] o oposto do amor não é o ódio, é a indiferença, e nela os seres não se encontram nem permanecem juntos". Daí que longe da neutralidade, um olhar atento e cuidadoso para aquela criança, demonstrou a amorosidade que envolve a postura da Educadora para com aquela e outras crianças hospitalizadas. Também foi possível vivenciar esse olhar sensível e atencioso na ação da Educadora, quando uma intercorrência aconteceu no momento da sua prática:

\footnotetext{
Fomos até o quarto do garoto e ele estava acordado [...] quem o acompanhava nesse dia era a tia, porém ela tinha saído. Ficamos com ele até que sua tia retornasse, o que não demorou a acontecer. Carlos começou a chorar. A Educadora nesse momento alertou a tia para a possibilidade de que ele estivesse se engasgando, mas a tia comunicou que o menino estava sentido dores na barriga e que se ele não se acalmasse iria chamar a enfermeira. Nesse instante, houve uma intercorrência. Carlos golfou de modo abundante. A Educadora rapidamente levantou a cabeça dele para que não se sufocasse e pediu para que eu acionasse a enfermaria. A enfermeira chegou logo em seguida. A acompanhante explicou para a profissional da saúde que isso não tinha acontecido antes enquanto ela estava por lá (DC-III).
}

Desta situação depreendemos que ter o conhecimento técnico, o saber-fazer com a criança hospitalizada em um momento de intercorrência é fundamental para um adequado trabalho do/a Educador/a de Classe Hospitalar. Ou seja, este saber-fazer também é imprescindível para a devida atenção e cuidado com outrem. As especificidades do contexto da Classe Hospitalar podem ser permeadas de acontecimentos que geram processos educativos significativos para todos/as os/as envolvidos/as, seja no desenvolvimento integral dos/as educandos/as ou nas aprendizagens do fazer profissional do/a educador/a.

Acerca da prática pedagógica no ambiente hospitalar a Educadora participante da pesquisa relatou ter participado de alguns congressos e que as experiências vividas nestes eventos agregaram em suas ações no cotidiano da Classe Hospitalar, mencionou, por exemplo, ter aprendido que "[...] no Hospital de [nome da cidade do interior do estado de São Paulo] há uma equipe para o atendimento das crianças a partir do quadro clínico, melhor observando cada necessidade, respectivo tempo de hospitalização e planejamento das atividades" (DC-IV). A Educadora frisou a relevância de pensar desde a organização dos recursos até a fundamentação teórica que respaldam os conteúdos trabalhados na prática pedagógica que ao serem discutidos entre especialistas da área contribuem para reflexões essenciais amparando a práxis e trazendo maior sustentação e qualidade para o trabalho (DC-IV).

Por fim, a atenção e o cuidado voltados para crianças hospitalizadas a partir da perspectiva lúdica contribuíram com a construção de laços de confiança e amorosidade na prática do Atendimento Educacional Hospitalar, relevantes para o atendimento humanizado em Educação e Saúde.

\section{CONSIDERAÇõeS}

O desenvolvimento deste estudo possibilitou identificar e compreender os processos educativos emergentes da prática social do Atendimento Educacional Hospitalar em uma perspectiva lúdica junto a uma classe de hospital de cidade do interior do estado de São Paulo. 
Consideramos que a atenção e o cuidado da Educadora da Classe Hospitalar, a partir da perspectiva lúdica, possibilitaram processos educativos como: amorosidade, diálogo e construção de laços de confiança, contribuindo com a ressignificação do contexto de hospitalização vivenciado pelas crianças.

A mediação lúdica pode auxiliar a ressignificação da realidade da hospitalização das crianças em geral, transformando e auxiliando seu processo de tratamento em busca da cura. Também se faz ímpar afirmar como imprescindível o Atendimento Educacional Hospitalar na garantia do direito à educação para crianças hospitalizadas.

Entendemos, com base no estudo, fundamental a compreensão do campo da educação em espaços como o hospitalar, trazendo reflexões consideráveis nesse sentido, bem como para eventuais ações no campo escolar convencional, sobretudo, implementando mediação lúdica, fundamentada na convivência respeitosa e amorosa (BOFF, 2006; FREIRE, 1992; OLIVEIRA et al., 2014; MATURANA; VERDENZOLLER, 2004) junto às crianças.

Contudo, reconhecemos a necessidade de aprofundamentos teórico-metodológicos e, sobretudo, de mais tempo de convivência com os/as colaboradores/as para aprimoramento deste estudo, melhor aproveitando as premissas da pesquisa participante (BRANDÃO, 2006; BRANDÃO; BORGES, 2008), em conhecer, desvelar, compreender para formar pessoas mais motivadas à transformação de seus mundosvida.

\section{REFERÊNCIAS}

BAUMAN, Z. Amor líquido. São Paulo: Zahar, 2014.

BOFF, L. Virtudes para um outro mundo possível: convivência, respeito e tolerância. Petrópolis: Vozes, 2006.

BOGDAN, R; BIKLEN, S. Notas de campo. In: BOGDAN, R; BIKLEN, S. Investigação qualitativa em educação: uma introdução à teoria e aos métodos. Porto: Porto Editora, 1994. p. 150-175.

BRANDÃO, C. R. Pesquisa participante: o saber da partilha. 2. ed. Aparecida: Ideias e Letras, 2006.

BRANDÃO, C. R.; BORGES, M. C. A pesquisa participante: um momento da educação popular. Revista de Educação Popular, Uberlândia, v. 6, n.1, p. 51-62, 2008.

BRASIL. Secretaria-Geral. Lei n. 13.716 de 24 de setembro de 2018: Altera a Lei $\mathrm{n}^{\circ}$ 9.394, de 20 de dezembro de 1996 (Lei de Diretrizes e Bases da Educação Nacional), para assegurar atendimento educacional ao aluno da educação básica internado para tratamento de saúde em regime hospitalar ou domiciliar por tempo prolongado. Brasília: Secretaria-Geral, 2018. Disponível em: http://www.planalto.gov.br/ccivil_03/_ato2015-2018/2018/lei/L13716.htm. Acesso em: 18 dez. 2020.

BRASIL. Ministério da Educação. Resolução $\mathbf{n}^{\mathbf{0}}$ 5, de 17 de dezembro de 2009: Fixa as Diretrizes Curriculares Nacionais para a Educação Infantil. Brasília: MEC, 2009. Disponível em: http://portal.mec.gov.br/index.php?option=com_docman\&view=download\&alias=2298-rceb005-

09\&category_slug=dezembro-2009-pdf\&Itemid=30192. Acesso em: 18 dez. 2020.

BRASIL. Ministério da Educação. Política nacional de educação especial na perspectiva da educação inclusiva. Brasília: MEC/SECADI, $2008 . \quad$ Disponível em: http://portal.mec.gov.br/arquivos/pdf/politicaeducespecial.pdf. Acesso em: 18 dez. 2020.

BRASIL. Ministério da Educação. Ensino fundamental de nove anos: orientações para a inclusão da criança de seis anos de idade. Brasília: MEC/SEB, 2007. 
Miriã Martins de Brito

BRASIL. Ministério da Educação. Classe hospitalar e atendimento pedagógico domiciliar: estratégias e orientações. Brasília: MEC; SEESP, 2002.

BRASIL. Ministério da Saúde. Programa nacional de humanização da assistência hospitalar. Brasília: Ministério da Saúde, 2001. Disponível em: http://bvsms.saude.gov.br/bvs/publicacoes/pnhah01.pdf. Acesso em: 18 dez. 2020.

BRASIL. Casa Civil. Lei n. 9.394, de 20 de dezembro de 1996: Estabelece as diretrizes e bases da educação nacional. Brasília: Casa Civil, $1996 . \quad$ Disponível em: http://www.planalto.gov.br/ccivil_03/leis/19394.htm. Acesso em: 18 dez. 2020.

BRASIL. Ministério da Educação. Política nacional de educação especial. Brasília: MEC/SEESP, 1994.

CARDOSO, M. R. Desafios e possibilidades da ludicidade no atendimento pedagógico hospitalar. 2011. 136 f. Dissertação (Mestrado em Educação) - Universidade de Brasília, Brasília, 2011.

COSTA, S. A. Diário de campo como dialética intersubjetiva. In: WHITAKER, D. C. A. (org.). Sociologia rural: questões metodológicas emergentes. Presidente Venceslau: Letras à Margem, 2002. p. 151-157.

DUARTE, C. F. Pedagogia hospitalar: o lúdico como um constructo da psicomotricidade. Revista de Pesquisa Interdisciplinar, v. 2, n. 2, p.829-833, 2017.

FONTES, R. S. A escuta pedagógica à criança hospitalizada: discutindo o papel da educação no hospital. Revista Brasileira de Educação, n. 29, p. 119-139, 2005.

FREIRE, P. Pedagogia do oprimido. 63. ed. Rio de Janeiro: Paz e Terra, 2017.

FREIRE, P. Pedagogia da esperança: um reencontro com a pedagogia do oprimido. 13. ed. Rio de Janeiro: Paz e Terra, 1992.

GOMES, R. Análise de dados em pesquisa qualitativa. In: MINAYO, C. O. Pesquisa social: teoria, método e criatividade. 21. ed. Petrópolis: Vozes, 2002. p. 67-80.

GONÇALVES JUNIOR, L.; CARMO, C. S.; CORRÊA, D. A. Cicloviagem, lazer e educação ambiental: processos educativos vivenciados na Serra da Canastra. Licere, v. 18, n. 4, p. 173-208, 2015.

GONÇALVES, A. G.; MANZINI, E. J. Classe hospitalar: poesia, texto e contexto de crianças e adolescentes hospitalizados. Marília: ABPEE, 2011.

MARINHO, A.; PIMENTEL, G. G. A. Dos clássicos aos contemporâneos: revendo e conhecendo importantes categorias referentes às teorias do lazer. In: PIMENTEL, G. G. A. Teorias do lazer. Maringá: EdUEM, 2010. p. 11-42.

MASSA, M. S. Ludicidade: da etimologia da palavra à complexidade do conceito. Aprender - Caderno de Filosofia e Psicologia da Educação, v. 1, n.15, p. 111-130, 2017.

MATURANA, H. R.; VERDEN-ZOLLER, G. Amar e brincar: fundamentos esquecidos do humano do patriarcado à democracia. São Paulo: Palas Athena, 2004.

MEDEIROS, J. G.; GABARDO, A. A. Classe hospitalar: aspectos da relação professor-aluno em sala de aula de um hospital. Interação em Psicologia, v. 8, n. 1, p.67-79, 2004.

MINEIRO, M.; D’ÁVILA, C. Ludicidade: compreensões conceituais de pós-graduandos em educação. Educação e Pesquisa, v. 45, n.1, p. 1-21, 2019.

OLIVEIRA, L. M.; SOUZA FILHO, V. C.; GONÇALVES, A. G. Classe hospitalar e a prática da pedagogia. Revista Científica Eletrônica de Pedagogia, Garça, v. 6, n. 11, p. 1-5, 2008. 
OLIVEIRA, M. W.; SILVA, P. B. G.; GONÇALVES JUNIOR, L.; MONTRONE, A. V. G.; JOLY, I. Z. L. Processos educativos em práticas sociais: reflexões teóricas e metodológicas sobre pesquisa educacional em espaços sociais. In: OLIVEIRA, M. W.; SOUSA, F. R. (org.). Processos educativos em práticas sociais: pesquisas em educação. São Carlos: EdUFSCar, 2014. p. 29-46.

OLIVEIRA, T. C. Um breve histórico sobre as classes hospitalares no Brasil e no Mundo. In: CONGRESSO NACIONAL DE EDUCAÇÃO, 11., 2013, Curitiba. Anais [...]. Curitiba, 2013. p. 1-13.

PAULA, T. C.; SOARES, Z. M. P. Classes hospitalares: a integração entre saúde e educação como um direito legítimo da criança e do adolescente. Cadernos da Pedagogia, São Carlos, v. 12, n. 23, p. 65-80, 2018.

PINTO, L. M. S. M. Vivências lúdicas no lazer: humanização pelos jogos, brinquedos e brincadeiras. In: MARCELLINO, N. C. (org.). Lazer e cultura. Campinas: Alínea, 2007. p. 171-193.

RIBEIRO, C. A.; ANGELO, M. O significado da hospitalização para a criança pré-escolar: um modelo teórico. Revista da Escola de Enfermagem da USP, São Paulo, v. 39, n. 4, p. 391-400, 2005.

SANTOS, P. M.; SILVA, L. F.; DEPIANTI, J. R. B.; CURSINO, E. G.; RIBEIRO, C. A. Os cuidados de enfermagem na percepção da criança hospitalizada. Revista Brasileira de Enfermagem, v. 69, n. 4, p. 646-653, 2016.

VENDRAMIN, M. J. S. C.; FERNANDES, R.; MATTÃO, P. Os benefícios do lúdico na pedagogia hospitalar. Núcleo Interdisciplinar de Pesquisa, Faculdades Promove de Brasília, p. 1-14, 2016.

ZAIAS, E.; PAULA, E. M. A. T. A produção acadêmica sobre práticas pedagógicas em espaços hospitalares: análise de teses e dissertações. Educação Unisinos, v. 14, n. 3, p. 222-232, 2010.

Recebido em: 07 jul. 2021.

Aprovado em: 07 set. 2021. 